\title{
Análise do Programa REUNI na UNIFESP (2008 a 2012) por uma perspectiva institucional e estudantil.
}

\begin{abstract}
Almeida, F. L.
Resumo - Nesse trabalho, o Programa de Apoio a Planos de Reestruturação e Expansão das Universidades Federais (REUNI), os jornais institucionais e as atas do Conselho Universitário da Universidade Federal de São Paulo (CONSU-UNIFESP) foram analisados considerando as perspectivas institucionais sobre o REUNI na UNIFESP (2008 a 2012). Por outro lado, os posicionamentos estudantis a respeito do mesmo (forjados, principalmente, em tempos de greves, mobilizações e reivindicações) foram examinados frente à política neoliberal governamental e aos desdobramentos entre as relações do trabalho e da agregação de capital financeiro na educação. A partir de uma análise metodológica marxista, a expansão do ensino superior federal (durante os governos de Luiz Inácio Lula da Silva e Dilma Rousseff) e o processo de intensificação das políticas econômicas na educação foram explanados estabelecendo um nexo crítico com a bibliografia que discute as políticas de cunho mercantilistas, privatistas e utilitaristas. Por fim, cabe a nós uma reflexão: a execução das metas REUNI implicou na precarização ou no fortalecimento do ensino superior público?
\end{abstract}

Palavras-chave: Movimento Estudantil. Expansão educacional. Ensino superior federal. REUNI.

\section{Introdução}

Esse estudo foi centrado na metodologia de análise qualitativa e quantitativa dos indicadores e documentos oficiais publicados entre 2003 e 2012 a respeito da expansão das universidades federais, especialmente a da UNIFESP. Por um lado, foram analisados o Programa (instituído pelo Poder Executivo por meio do Decreto ${ }^{\circ}$ 6.096, de 24 de abril de 2007) e as Diretrizes REUNI [elaboradas pelo Ministério da Educação (MEC), durante o segundo mandato do Presidente Luiz Inácio Lula da Silva (2007-2010) e os primeiros anos do governo Dilma Rousseff (2011-2012)], alguns relatórios do Ministério da Educação (MEC) e da Controladoria Geral da União (CGU), os jornais institucionais e atas do Conselho Universitário (CONSU) e a proposta da UNIFESP para adesão ao REUNI. Por outro lado, os documentos (boletins, jornais e atas de reunião) produzidos pelo Movimento Estudantil da Universidade de São Paulo (ME-UNIFESP) - foco no CR-DCE ${ }^{1}$ e DCE-UNIFESP - foram estudados identificando os posicionamentos do ME-UNIFESP diante do REUNI na UNIFESP (2008 a 2012). A maioria desses documentos foi produzido, principalmente, em tempos de mobilizações e greve, de acirramento das contradições universitárias ou de reivindicações não contempladas.

Neste contexto, a partir das palavras-chave de referência (acesso restrito à educação/ensino superior, políticas educacionais recentes, expansão da educação ou do ensino superior, movimento estudantil, UNIFESP, REUNI) foi realizada uma extensa pesquisa bibliográfica usando as bases de

1 Do Estatuto do DCE-UNIFESP: artigo 21 - O Conselho Representativo do DCE, doravante designado CR-DCE, é a instância deliberativa imediatamente abaixo da Assembléia Geral [Estudantil (AGE)] e é composto pelos representantes dos Centros Acadêmicos (CAs), Associações Acadêmicas (AAs), Diretórios Acadêmicos (DAs), pelo DCC e pela Diretoria do DCE. 
dados científicos Scielo, SciVerse Scopus e, Google Acadêmico e dos sites da CGU, do MEC e da UNIFESP. Posteriormente, ao longo desta pesquisa, os resultados obtidos foram sistematizados e avaliados a partir de referencial teórico marxista e da literatura que discute a expansão recente do ensino superior e as políticas neoliberais governamentais emplacadas na educação.

\section{Cenário político e econômico do Brasil entre 2003 e 2012.}

Os autores Lima, Kátia (2006), Leher (2003 e 2004) e Tecedor (2010) abordaram as políticas governamentais recentes para a educação ${ }^{2}$ como ações que privilegiaram o setor privado em detrimento ao público, recebendo influências diretas da economia privada, das Organizações Internacionais - o Banco Mundial, o Fundo Monetário Internacional (FMI) e o Banco Internacional para Reconstrução e Desenvolvimento (BIRD) são exemplos -, de outros setores da economia que atuem na manutenção do sistema do capital financeiro e das políticas reducionistas, minimizando o papel do Estado frente à educação pública. Por outro lado, entre os defensores das políticas governamentais, Araújo e Pinheiro (2010, p.661) afirmaram:

o REUNI deve estruturar-se em seis dimensões que devem ser combinadas no plano de reestruturação: ampliação da oferta de educação superior pública, reestruturação acadêmico-curricular, renovação pedagógica da educação superior, mobilidade intra e interinstitucional, compromisso social da instituição, suporte da pós-graduação ao desenvolvimento e aperfeiçoamento qualitativo dos cursos de graduação.

As políticas governamentais recentemente implementadas no ensino superior brasileiro (BRASIL, 2012), geralmente, estão amparadas no discurso: houve expansão rumo à universalização do ensino superior (LIMA, Paulo, 2013), à democratização do acesso à educação pública (DIAS SOBRINHO, 2013) e à ampliação da permanência, da assistência e da inclusão estudantil (ARAÚJO; PINHEIRO, 2010). Discursos consonantes com o REUNI, seja pelo "aumento de vagas para a graduação seja por vagas de ingresso ou reocupação de vagas ociosas" (BRASIL, 2007, p. 24) e pela "oferta de meios e condições para permanência e sucesso dos estudantes na realização da formação superior" (BRASIL, 2007, p. 24).

Os desdobramentos críticos a respeito das políticas governamentais recentes para a educação superior se fundamentam em uma análise direcionada à "reforma universitária"3 governamental, apontando as controvérsias universitárias. Portanto, defender a educação pública, gratuita, laica, presencial e de qualidade/excelência sem contextualizá-la historicamente à conjuntura política e

\footnotetext{
2 “As principais ações políticas [...] foram: [...] o Programa Universidade para Todos (ProUni), o Sistema Nacional de Avaliação da Educação Superior (Sinaes), a Lei de Inovação Tecnológica, a educação à distância e as Parceria Público-Privadas" (TRÓPIA, 2009, p. 3), incluímos também, o Programa de Apoio a Planos de Reestruturação e Expansão das Universidades Federais (REUNI), a criação do Sistema Unificado (SiSu), o Exame Nacional do Ensino Médio (Enem) e as políticas afirmativas de cotas raciais (SOUZA, 2012).

3 Durante os governos de Luiz Inácio Lula da Silva (2003-2010), diversos projetos e programas foram implementados na educação superior. Este conjunto de políticas governamentais ficou conhecido como "reforma universitária"; doravante a "reforma universitária" será analisada sob os aspectos mercantis, utilitaristas e regressivos (TRÓPIA, 2009, p. 4) introjetados no ensino superior brasileiro.
} 
social, estamos sujeitos a compactuar com uma perspectiva de universidade elitista. Souza (2012) alerta-nos desse perigo e discute a universidade pelo horizonte classista.

Nesse sentido que segundo Mészáros (2008 apud Nascimento Silva, 2012, p 17), a educação deve ser transformadora, para além do capital financeiro, ou seja, rompendo com a lógica de subordinação aos interesses econômicos. Nascimento Silva apóia-se nos estudos de Mészáros e corrobora para a compreensão das políticas governamentais no contexto da expansão recente do ensino superior federal que ocorreu e ocorre mediante o avanço do capital financeiro. Dialogando com Nascimento Silva (2012), Souza (2012), Trópia (2009) e Lima, Kátia (2006), considera-se “a política neoliberal ${ }^{4}$, apesar de amplamente dominante, encontra-se em disputa” (TRÓPIA, 2009, p. 1). Trópia (2009) também discute a flexibilização ${ }^{5}$ do sistema de ensino superior; ela comenta que as universidades comprometidas com o REUNI significaria a implementação do polêmico modelo de ensino flexível com alguma suplementação de recursos financeiros.

\section{REUNI na UNIFESP e os indicadores}

"Nos dias 8 e 9 de dezembro [de 2006 no fórum "Novos Rumos da UNIFESP], cerca de duzentas pessoas puderam discutir as mudanças ocorridas na instituição [UNIFESP] e apresentar suas dúvidas, preocupações e contribuições para o aperfeiçoamento da UNIFESP." (JORNAL UNIFESP/SPDM, 2007, grifo nosso). O evento recebeu o reitor da UNESP, Marcos Macari, que falou sobre o desafio de integrar campi com características distintas e geograficamente separados, e o diretor da Secretaria de Ensino Superior do MEC, Manuel Palácios, representando o ministro da educação Fernando Haddad. Palácios abordou o Programa de Expansão das Instituições Federais de Ensino Superior (IFES), iniciado a partir do Decreto S/N de 20 de outubro de 2003 do Governo Federal (BRASIL, 2003). No segundo dia do fórum, Manuel Palácios, Prof. Dr. Ulysses Fagundes Neto (reitor da UNIFESP em 2006) e Francisco Lacaz (presidente da Adunifesp - 2006) discutiram

sobre a necessidade de se buscar formas inovadoras de gerir as universidades públicas. Flexibilização das normas de ingresso, da estrutura de cursos e de departamentos; democratização das instâncias decisórias e implantação de uma real cultura de avaliação e reconhecimento do mérito foram apenas algumas das propostas debatidas. (JORNAL UNIFESP/SPDM, 2007).

Comitantemente ou inspiradamente, o Programa REUNI germinava-se no âmbito do poder Executivo Federal em mesma época. No ano de 2007, "a proposta de adesão ao plano do REUNI, como foi apresentada ao Conselho Universitário da Universidade Federal de São Paulo (CONSUUNIFESP), foi colocada em votação pelo reitor [Ulysses], que foi aprovada com 32 votos a favor, 4

$4 \quad$ Política neoliberal expressa o conjunto que abarca a lógica de flexibilização do ensino e da captação de recursos financeiros da iniciativa privada, a educação como mercadoria, a terceirização e privatização dos serviços públicos e a formação superior voltada para o mercado de trabalho (empregabilidade).

5 A flexibilização do ensino superior inclui a abertura de cursos sequenciais de curta duração e noturnos, os Bacharelados Interdisciplinares (BIs), as alterações estruturais no currículo acadêmico, na contratação de professores e na gestão dos recursos financeiros e "a redução custo por aluno" (TRÓPIA, 2009, p. 4). 
votos contrários e 9 abstenções" (CONSU-UNIFESP, 2007). Pelos números da votação, fica notório o amplo apoio pela maioria dos membros do CONSU-UNIFESP na aprovação da proposta de adesão ao REUNI. Importante enfatizar, não houve nenhuma alteração na proposta original de adesão ao REUNI apresentada ao CONSU do dia 17/10/2007. Duas hipóteses para a aprovação do REUNI na UNIFESP sem discussões e modificações, a maioria do CONSU confiava plenamente na condução do processo de expansão pela reitoria (sem questionamentos) ou a maioria do CONSU não conhecia suficientemente (inexperiência) o Programa REUNI para opinar, pelo menos no que tange o REUNI e a pactuação de metas entre a UNIFESP e o MEC.

Em 2007, os campi Guarulhos, São José dos Campos e Diadema iniciavam suas atividades acadêmicas e o Campus Baixada Santista estava com um ano de funcionamento em cursos de graduação; todos os campi com inúmeros problemas de infraestrutura, de falta de professores e de técnico-administrativos em educação (TAE) e etc. No encontro (em 2007) do reitor Ulysses com o Ministro da Educação Fernando Haddad, foi discutido por ambos a abertura do novo campus da UNIFESP em Osasco. O Campus Osasco foi inaugurado no ano de 2010, com semelhantes problemas ocorridos nos campi da expansão: falta de biblioteca e internet, de lanchonete e restaurante universitário, de professores e TAE e de diversos serviços de manutenção do campus.

Passados alguns meses da aprovação da proposta de adesão ao REUNI pela UNIFESP, os membros do Conselho Universitário participam da primeira atividade informativa sobre o REUNI (registrada em ata do CONSU-UNIFESP). Em Tribuna Aberta, o Prof. Luiz Eugênio A. M. Mello:

\begin{abstract}
relembrou que o projeto [REUNI] começou a ser elaborado em abril de 2007 e envolveu um grande número de servidores de todos os campi. Disse que foi solicitado um conjunto de recursos e que fomos aquinhoados com $\mathrm{R} \$ 98$ milhões de reais para contratação de docentes e servidores técnico-administrativos [em educação]; $R$ \$ 49 milhões para bolsas de assistência estudantil, mestrado e doutorado; $\mathrm{R} \$ 44$ milhões para infraestrutura/edificações, totalizando um número expressivo de mais de $\mathrm{R} \$ 190$ milhões que serão encaminhados até o ano de 2012. Demonstrou o cronograma geral de implementação e execução, detalhando que o número de cursos serão ampliados dos atuais 23 para 41 até 2012. O número de vagas de ingresso passará das 1.150 atuais para 2.598 e os cursos noturnos de 250 para 690 . Ressaltou que em 2017 estaremos com 10.487 alunos contra os 2.300 atuais e a contratação de 394 docentes além dos já pactuados antes do REUNI que totalizarão 714 docentes. Falou sobre a expansão da Pós-graduação, incluindo os novos campi, com 496 novos orientadores, como também a contratação de 375 [TAEs], que anteriormente ao REUNI seriam 116, para toda administração. CONSU-UNIFESP (2008).
\end{abstract}

Tabela 1 - Quadro-síntese de alguns indicativos de avaliação na graduação presencial (UNIFESP - todos os campi), base para a análise das metas ou das reivindicações estudantis. ND: não disponível.

\begin{tabular}{|c|c|c|c|c|}
\hline & Anos & 2004 & 2008 & 2012 \\
\hline Indicadores de avaliação ou reivindicações estudantis & & $\begin{array}{l}\text { Antes da } \\
\text { expansão }\end{array}$ & REUNI & REUNI \\
\hline Alunos diplomados & & ND & 272 & 792 \\
\hline Processos para aquisição de acervo bibliográfico (meta/realizado) & & $500 / 0$ & $260 / 260$ & ND \\
\hline Custo Corrente total UNIFESP sem HU (R\$) & & $306.500 .845,47$ & $378.657 .317,65$ & $513.500 .741,46$ \\
\hline Alunos regularmente matriculado & & 1.293 & 2.320 & 8.592 \\
\hline Cursos de graduação presencial & & 5 & 25 & 64 \\
\hline
\end{tabular}




\begin{tabular}{|c|c|c|c|}
\hline Vagas no sistema de flexibilização do ensino ${ }^{6}$ & 2.850 & 1.532 & 11.980 \\
\hline Inauguração de novos prédios com verba REUNI & 0 & 0 & 2 \\
\hline Docentes-equivalente & ND & 818,50 & 1319,00 \\
\hline TAEs-equivalente (sem HU) & ND & 1716,5 & 1884,25 \\
\hline Relação ponderada alunos/professor & 11,7 & 10,98 & 11,63 \\
\hline Grau de participação estudantil & 1,73 & 1,40 & 1,31 \\
\hline Taxa de Sucesso na Graduação & 0,97 & 0,928 & 0,242 \\
\hline
\end{tabular}

Fonte: elaborado pelo autor a partir dos relatórios de gestão UNIFESP (2004-2012).

A citação do Prof. Luiz Eugênio é importante, pois nos expõe um panorama de implementação do REUNI vislumbrando o ano de 2012. Ele buscou apresentar uma idéia de planejamento, discussão e envolvimento dos servidores (TAE) com a expansão da universidade e com o REUNI. Porém, entre 2006 e 2008, em nenhum momento nos materiais analisados de nossa pesquisa, há menção do REUNI pelos TAEs; neste caso, fica difícil sustentar os argumentos apresentados pelo Prof. Luiz Eugênio. Por fim, a Tabela 1 apresenta os indicadores antes (2004), no início (2008) e ao final (2012) do REUNI, que nos permite uma comparação do que se propunha com a adesão do REUNI com os resultados objetivamente efetivados.

\section{Posicionamentos do ME-UNIFESP diante do REUNI}

Em maio de 2005, há o primeiro registro da participação dos estudantes no processo de expansão da UNIFESP. Em Tribuna Aberta "Rumos da UNIFESP/EPM" do CONSU-UNIFESP (2005c), o estudante Fabrício Chaves Martins abordou a expansão da UNIFESP no sentido de garantir os recursos financeiros e viabilizar o tripé do ensino, pesquisa e extensão. Nesta ocasião, o reitor [Ulysses] disse que também acha fundamental estabelecer as regras antes de iniciar qualquer projeto, mas no nosso país temos que criar e em seguida ousar, a fim de conseguir recursos e crescer (CONSU-UNIFESP, 2005). O Reitor Ulysses, ciente das críticas e das consequências de uma expansão feita "às pressas", insiste em sustentar um processo de expansão da UNIFESP sem registrar e assumir as reivindicações estudantis; pelo contrário, marginalizava e ignorava-as.

Pelo âmbito estudantil, havia poucas discussões até a chegada do REUNI. O primeiro posicionamento dos estudantes sobre o REUNI foi relatado como uma proposta de discussão em reunião do DCE-UNIFESP (2007), pois somente caberia aos estudantes realizar modificações no projeto apresentado e aprovado em 17/10/2007 pelo CONSU. Em nenhum momento, os estudantes se manifestaram contra a expansão de vagas no ensino superior. Os estudantes não compactuaram com o processo de expansão sem planejamento conduzido pela UNIFESP. O posicionamento contrário ao REUNI, em grande medida, deve-se às promessas parcialmente ou não cumpridas, por exemplo: moradia estudantil em todos os campi. Por fim, entre 2010 e 2012, o ME-UNIFESP

6 Entre outros, o curso superior de formação específica sequencial da UNIFESP: Gestão em Saúde (UNIFESP, 2004-2012); e Universidade Aberta, BIs e Ensino à Distância. 
(2011) se posicionou enfaticamente contra a lógica mercantilista, privatista e utilitarista que assolou e assola as universidades e que constrói um espaço pouco propício à absorção das demandas sociais.

Transpondo a tese de Cuadra (2008, p. 185) para a UNIFESP, no lugar de assumir a iniciativa e registrar as reivindicações estudantis, a UNIFESP tratou os posicionamentos estudantis como algo que pudesse resolver por si mesmo, na mesma lógica neoliberal de "auto-regulação" do mercado (similar à postura do governo chileno diante das mobilizações estudantis de abril de 2006). Muitas vezes, os dirigentes da UNIFESP internalizaram uma forma empresarial de administração e de condução da universidade, sem associá-la ao conteúdo universitário, às demandas estudantis, à sociedade civil e à vida em geral, como se observou na mobilização estudantil de maio de 1968 em Paris (THIOLLENT, 1998). Em alguns momentos, a radicalização estudantil esteve presente. Dialogando com Lénine (1920), "o erro consistiu em negar-se a participar no parlamento reacionário, burguês, e nos sindicatos reacionários”. Esses estudantes descartavam quaisquer possibilidades de ação política nas instâncias institucionais de decisão UNIFESP e o DCE era visto como propagador dos interesses da universidade. Em contrapartida, os estudantes mais moderados e a ala dirigente da universidade se apegavam ao discurso da radicalização do ME-UNIFESP para deslegitimar as mobilizações.

\section{Conclusões}

Antes do REUNI na UNIFESP (2008), a ideologia e as políticas do Programa REUNI já estavam em marcha na expansão da universidade (a partir de 2004) e; quiçá, na elaboração do Programa REUNI em si a ser lançado pelo Governo Federal em 2007. Conclui-se que a execução do Programa REUNI, em certa medida, intensificou problemas, considere-se:

i) a proposta de adesão ao REUNI pela UNIFESP não foi amplamente discutida com a comunidade UNIFESP;

ii) a expansão UNIFESP sem planejamento refletiu no agravamento das deficiências administrativas, principalmente, nos novos campi e no acirramento político entre o MEUNIFESP e a reitoria;

iii) técnicos, acervo bibliográfico e novas edificações foram os mais negligenciados;

iv) a verba para a expansão foi mitigada e vinculada ao cumprimento de metas na expansão de vagas e redução do custo anual por aluno-equivalente; e

v) na maioria dos casos, a UNIFESP marginalizou as reivindicações estudantis e assumiu uma inclinação ao projeto neoliberal proposto pelo Governo Federal, encampando a flexibilização do ensino superior.

\section{Referências}

ARAÚJO, M. A. D.; PINHEIRO, H. D. Revista Ensaio: [...], Rio de Janeiro, v. 18, n. 69, p. 647-668, out./dez. 2010. BRASIL. Análise sobre a expansão das universidades federais [...]. Ministério da Educação (MEC). Brasília, 2012. Diretrizes gerais do programa [...] REUNI. Ministério da Educação (MEC). Brasília, 2007. Decreto $\mathbf{s} / \mathbf{n}^{\mathbf{0}}$, de 20 de outubro de 2003. Brasília, 2003.

CONSU-UNIFESP. Ata da reunião ordinária [...]. São Paulo, 17 out. 2007. São Paulo, 2007. Ata da reunião ordinária [...]. São Paulo, 09 mar. 2005. São Paulo, 2005. 
Ata da reunião ordinária [...].São Paulo, 13 fev. 2008. São Paulo, 2008.

CUADRA, F. Estudos Históricos, Rio de Janeiro, v. 21, n. 42, p. 173-194, jul.-dez. 2008.

DCE-UNIFESP. Ata da reunião do Diretório Central dos Estudantes [...]. São Paulo, 2007. Arquivo digital.

O Manuscrito. Ed. Especial Calouros 2011. São Paulo, 2011. Arquivo digital.

DIAS SOBRINHO, J. Avaliação, Campinas; Sorocaba, v. 18, n. 1, p. 107-126, mar. 2013.

JORNAL UNIFESP/SPDM. Informativo do complexo UNIFESP/SPDM, n. 12, jan. 2007. São Paulo, 2007.

LÉNINE, V. I. Esquerdismo: doença infantil do Comunismo, 19205 ed., Brasil: Global Editora.

LIMA, Kátia. Caderno Especial, n. 30. 2006.

LIMA, Paulo G.. Avaliação, Campinas, v. 18, n. 1, p. 85-105, mar. 2013.

LEHER, R. Educação \& Sociedade, Campinas, v. 25, n. 88, p. 867-891, out. 2004.

Trabalho, Educação e Saúde, v. 1, n. 2, p. 203-228, 2003.

NASCIMENTO SILVA, M. P. O processo de greve dos professores da UNICASTELO no ano de 2010 e seus reflexos para a formação profissional dos estudantes de serviço social. 2011. 141 p. (Monografia). Universidade Camilo Castelo Branco, Curso de Serviço Social, São Paulo, 2011.

SOUZA, D. C. Revista Pensata, v. 2, n. 1, p. 55-71, dez. 2012.

TECEDOR, T. L. A. A formação profissional e o Ensino a Distância: o desafio de se forjar um profissional comprometido com o projeto ético-político profissional versus a realidade da educação brasileira. 2010 . $154 \mathrm{f}$. (Monografia). Pontifícia Universidade Católica de São Paulo (PUC-SP), São Paulo, 2010.

THIOLlENT, M. Tempo Social, São Paulo, v. 10, n. 2, p. 63-100, out. 1998.

TRÓPIA, P. V. Revista Iberoamericana de Educación, v. 49, n. 3, abr. 2009. 